\title{
ANÁLISE DOS NÍVEIS DE ATENDIMENTO DOS DISPOSITIVOS DA NR 9 E NR 31 EM GRANJAS SUINÍCOLAS DO OESTE CATARINENSE
}

\author{
MARIN, Gianne ${ }^{1}$ \\ CAMARGO, Tiago Francisco de ${ }^{1}$ \\ ZANIN, Antonio ${ }^{1}$
}

\begin{abstract}
RESUMO: Esta pesquisa objetivou identificar os níveis de atendimento das Normas Regulamentaras (NR) 9 e 31 no desenvolvimento das atividades suinícolas das granjas do oeste catarinense.. Com relação aos aspectos metodológicos realizou-se uma pesquisa descritiva e exploratória através de procedimentos bibliográficos e documental. Quanto a técnica para coleta dos dados de campo, realizou-se por meio de um questionário estruturado, aplicado através de survey em 265 granjas suinícolas da região oeste de Santa Catarina no período entre Agosto de 2015 e Junho de 2017. Os dados foram tabulados em planilha Excel com abordagem quali-quantitativa do problema. Quanto ao nível de atendimento NR 9 e NR 31 no que se refere a responsabilidade de realizar treinamentos do empregador ou equiparado, os produtores declararam que 58\% não atendem, $34 \%$ atendem em partes e $8 \%$ atendem totalmente. Com relação ao nível de atendimento da NR 31.20, sobre os aspectos de treinamentos e disponibilização de Equipamentos de Proteção Individual, os principais resultados identificados permitem inferir que $14 \%$ do total de suinocultores entrevistados declararam que "Atendem totalmente". Sob os aspectos dos níveis de atendimento da NR 9, que trata da realização preventiva de Programa de Prevenção de Riscos Ambientais (PPRA), os principais resultados identificados permitem inferir que $6 \%$ do total de unidades produtoras pesquisadas afirmaram "Atender totalmente" os dispositivos desta NR. Conclui-se que os suinocultores do oeste catarinense estão vulneráveis, quanto ao nível de atendimento dos dispositivos da NR 9 e NR 31, justificados pelos resultados mais representativos de $(58 \%, 34 \%$ e $60 \%)$ de "Não atendimento".
\end{abstract}

Palavras-chave: Segurança no trabalho rural. Suinocultura. NR 9. NR 31.

\section{ANALYSIS OF THE LEVELS OF ATTENDANCE OF THE DEVICES OF NR 9 AND NR 31 IN WILDERNESS FARMS OF THE WEST CATARINENSE}

SUMMARY: This research aimed to identify the levels of Regulation Standards (NR) 9 and 31 in the development of pig farms activities in western Santa Catarina. With regard to the methodological aspects, a descriptive and exploratory research was carried out through bibliographical and documentary research. As for the field data collection technique, a structured questionnaire was carried out, for which a survey was carried out on 265 pig farms in the western region of Santa Catarina between August 2015 and June 2017. Data were tabulated in Excel spreadsheet with qualitative-quantitative approach of the problem. Regarding the level of attendance NR 9 and NR 31 with regard to the responsibility to perform training of the employer or equivalent, the producers declared that $58 \%$ do not meet, $34 \%$ attend in parts and $8 \%$ attend fully. Regarding the level of attendance of NR 31.20, regarding the aspects of training and availability of individual protection equipment, the main results identified allow to infer that $14 \%$ of the total pig farmers interviewed stated that" They fully respect ". Under the NR 9 levels of care, which deals with the preventive performance of environmental risk prevention program (PPRA), the main results identified allow us to infer that $6 \%$ of the total production units surveyed stated "Fully meet" the devices of this NR. Concluded that pig farmers in the west of Santa Catarina are vulnerable, regarding the compliance with the provisions of NR 9 and NR 31 , justified by the $(58 \%, 34 \%$ and $60 \%)$ of non-compliance with the provisions of the respective regulatory standards.

Keywords: Rural work safety. Pig breeding. NR 9. NR 31

\section{ANÁLISIS DE LOS NIVELES DE ATENCIÓN DE LOS DISPOSITIVOS DE LA NR 9 Y NR 31 EN GRANJAS DE CERDOS DEL OESTE CATARINENSE}

\footnotetext{
${ }^{1}$ Universidade Comunitária da Região de Chapecó
} 
RESUMEN: Esta investigación objetivó reconocer los niveles de atención de las Normas Regulatorias (NR) 9 y 31 en el desarrollo de las actividades porcinas de las granjas del Santa Catarina. Con relación a los aspectos metodológicos se realizó una investigación descriptiva y exploratoria a través de procedimientos bibliográficos y documental. En cuanto a la técnica de recolección de los datos de campo, se realizó a través de un cuestionario estructurado, aplicado a través de survey en 265 granjas porcinas de la región oeste de Santa Catarina en el período entre agosto de 2015 y junio de 2017. Los datos fueron tabulados en hoja de cálculo Excel con el enfoque cualitativo cuantitativo del problema. En cuanto al nivel de atención NR 9 y NR 31 en lo que se refiere a la responsabilidad de realizar entrenamientos del empleador o equiparado, los productores declararon que el 58\% no atiende, el 34\% atiende en partes y el $8 \%$ atiende totalmente. Con respecto al nivel de atención de la NR 31.20, sobre los aspectos de entrenamientos y puesta a disposición de Equipos de Protección Individual, los principales resultados identificados permiten inferir que el $14 \%$ del total de cerdos encuestados declaró que "Atendemos totalmente". En los aspectos de los niveles de atención de la NR 9, que trata de la realización preventiva de Programa de Prevención de Riesgos Ambientales (PPRA), los principales resultados identificados permiten inferir que el $6 \%$ del total de unidades productoras encuestadas afirmó "Atender totalmente" los dispositivos de esta NR. Se concluye que los creador de cerdo del oeste de Santa Catarina son vulnerables, en cuanto al nivel de atención de los dispositivos de la NR 9 y NR 31 , justificados por los resultados más representativos de $(58 \%, 34 \%$ y $60 \%)$ de "No atención".

Palabras clave: Seguridad en el trabajo rural. Porcino. NR 9. NR 31.

\section{INTRODUÇÃO}

As atividades relacionadas à suinocultura ocupam lugar de destaque na matriz produtiva do agronegócio brasileiro, destacando-se como uma atividade de importância econômica e social, em especial na geração de emprego, uma vez que a produção ocorre principalmente, em pequenas e médias propriedades rurais, nas quais se utiliza mão de obra familiar (SUINOCULTURA INDUSTRIAL, 2016). Segundo a Associação Brasileira de Proteína Animal (ABPA) a produção de carne suína em 2016 foi de 3.731 mil toneladas, sendo o estado de Santa Catarina é segundo maior produtor nacional desta proteína e o quarto maior exportador mundial.

Quanto a organização da cadeia produtiva de suínos na região sul do Brasil estima-se que $92 \%$ dos estabelecimentos suinícolas tecnificados sejam integrados, ou seja, vinculados por contratos ou programas de fomento pecuário com empresas e cooperativas agroindustriais (MIELE, 2006).

Torna-se relevante apresentar que na modalidade de negócio predominante "Integrada ou Cooperada", o produtor rural é um agente equiparado a funcionário, regido por contrato especifico de obrigações e responsabilidades. Sua participação na parceria consiste em investir valores altos em "estrutura" e "mão de obra" além de arcar com alguns gastos de produção como água e energia elétrica, juros sobre financiamentos, depreciações entre outros. No entanto, todo o estoque de animais, ração, medicamentos, assistência técnica, caracterizado como capital de giro da atividade é fornecido pela da agroindústria; sendo que o produtor não coordena atividade de produção, "apenas" precisa seguir as recomendações técnicas do Integrador. Por este motivo, entende-se que quando o produtor não possui funcionários, o "integrador" representante da agroindústria, equipara-se a condição de empregador para atendimento dos dispositivos da NR 9 e NR 31 (ENGELAGE et al., 2017).

No caso suinocultura do oeste catarinense, predomina-se o uso de mão de obra familiar no desenvolvimento das atividades para as granjas de porte médio ou pequeno, já as granjas de maior porte que demandam de contratação de funcionários para execução das funções. Este público está exposto diariamente a diversos riscos ocupacionais, principalmente os ergonômicos e de acidentes, que podem trazer comprometimento à sua saúde e à sua segurança do trabalhador (CAMARGO, 2017).

Para esclarecer dúvidas e procedimentos de situações como esta mencionada, entrou em vigor ainda em (2005) a Norma Regulamentadora (NR-31) que trata dos aspectos relativos à segurança 
segurança e saúde no trabalho na agricultura, pecuária, silvicultura, exploração florestal e aquicultura, com foco em garantir que os empregadores forneçam condições de trabalho, higiene e conforto para os trabalhadores através do estudo do ambiente, adotando medidas para controle dos riscos visando à preservação da saúde e da integridade física dos colaboradores no trabalho rural.

Dentre outros assuntos, que versa NR 31, existem itens próprios, sobre o uso de "agrotóxicos, adjuvantes e produtos afins" (31.8), assim com "medidas de proteção pessoal" (31.20), referindo-se à obrigatoriedade do uso de EPI e das responsabilidades do Empregador ou equiparado e também do funcionário.

De acordo com NR 9 e NR 31 não é suficiente somente o fornecimento do EPI pelo empregador ou equiparado. Há a obrigatoriedade da realização de treinamentos adequados para o trabalhador rural, já que o ambiente de trabalho torna complexa a supervisão e fiscalização destes dispositivos, durante a realização das atividades pelas autoridades competentes.

Diante do exposto formulou-se a seguinte questão de pesquisa: quais os níveis de atendimento dos dispositivos da NR 9 e NR 31 no desenvolvimento das atividades suinícolas das granjas do oeste Catarinense? Desta maneira, o objetivo da pesquisa consiste em identificar os níveis de atendimento da NR 9 e NR 31 no desenvolvimento das atividades suinícolas das granjas do oeste catarinense, classificando-as em: Atende totalmente; Atende em partes ou não atende.

A pesquisa justifica-se pois conforme Farias e Muller (2006) na suinocultura industrial, assim como em outras atividades agrícolas, é eminente os riscos de enfermidades ocupacionais provocadas por agentes físicos, químicos e biológicos que estão sempre presentes, sendo necessários a realização de diagnóstico e mapeamento de dispositivos para prevenir tais riscos, realizados através do PPRA.

Diferenciada da maioria das Normas Regulamentadoras, esta define obrigações constantes em outras NR, para as atividades rurais. Desta maneira a NR 31, tem por "objetivo estabelecer os preceitos a serem observados na organização no ambiente de trabalho, de forma a tornar compatível o planejamento e o desenvolvimento das atividades rurais". No entanto convém destacar que estudos sobre adequação e atendimento da NR 31 e NR 9 na cadeia de produção suinícola ainda são escassos, desta maneira esta pesquisa propõem-se a contribuir para informar a sociedade cientifica sobre os aspectos relativos a estes quesitos, assim como aguçar a provocação de discussão sobre esta temática.

\section{PROCEDIMENTOS METODOLÓGICOS}

Neste momento apresenta-se a metodologia científica utilizada no desenvolvimento da pesquisa, iniciando pela caracterização da estrutura metodológica, definição do Instrumento de coleta de dados, quantificação da amostra necessária, além do detalhamento dos procedimentos para análise dos dados relativos à avaliação do nível de atendimento da NR 9 e NR 31 nas granjas suinícolas do oeste catarinense.

Para a classificação da pesquisa buscou-se subsídios em Beuren et al., (2008) e Martins e Theóphilo (2016), que definem quatro formas para a classificação de uma pesquisa científica conforme exposto no Quadro 2. 
Quadro 1 Classificação metodológica da pesquisa.

\begin{tabular}{|l|l|l|}
\hline 1.Objetivos & $\begin{array}{l}\text { a) Descritiva } \\
\text { b) Exploratória }\end{array}$ & $\begin{array}{l}\text { a) Caracterização do perfil } \\
\text { b) Atendimento NR 9 e NR 31 }\end{array}$ \\
\hline 2.Procedimentos & $\begin{array}{l}\text { c) Bibliográfica } \\
\text { d) Documental }\end{array}$ & $\begin{array}{l}\text { c) a partir materiais já existentes NR } \\
\text { d) ainda sem tratamento analítico }\end{array}$ \\
\hline 3.Técnica Coleta de Dados & $\begin{array}{l}\text { Aplicação de } \\
\text { Levantamento/Survey }\end{array}$ & Questionário Estruturado \\
\hline 4.Abordagem dos dados & $\begin{array}{l}\text { e) Quantitativa } \\
\text { f) Qualitativa }\end{array}$ & $\begin{array}{l}\text { e) Perfil } \\
\text { f) Atendimento das NR 9 e NR 31 }\end{array}$ \\
\hline
\end{tabular}

Fonte: Beuren et al., (2008); Martins e Theóphilo (2016).

Quanto aos objetivos da pesquisa, considerou-se como uma pesquisa descritiva e exploratória, sendo que quanto aos aspectos da caracterização do Perfil dos suinocultores (descritiva) e quanto à análise do atendimento ou não das granjas suinícolas aos dispositivos previstos na NR 9 e NR 31 considera-se como uma pesquisa exploratória (RAUPP; BEUREN, 2008).

Conforme Gil (1999), os procedimentos de pesquisa são os elementos mais importantes para identificar o delineamento e a maneira utilizada para a coleta de dados. Neste aspecto, Martins e Theóphilo (2016) dispõem que a estratégia de pesquisa survey ou Levantamento pode ser utilizada para a coleta de dados proporcionando versatilidade como estratégia de pesquisa .

Quanto à forma de abordagem do problema, esta pesquisa se caracteriza como quali-quantitativa. Quanto aos aspectos quantitativos, estes caracterizam-se pelo emprego do uso de instrumentos estatísticos, tanto na coleta quanto no tratamento dos dados (RAUPP; BEUREN, 2008). Já no que tange o escopo dos aspectos qualitativos, segundo Martins e Theóphilo (2016), caracterizam-se por descrever a complexidade de determinado problema, e permitem analisar a interação entre as variáveis e a classificar fenômenos dinâmicos. Neste tipo de pesquisa as análises são mais profundas e podem produzir informações, que não são identificadas em um estudo numérico, de natureza quantitativa.

Para a pesquisa, selecionou-se 10 questões de um conjunto de 47 da pesquisa, em 265 granjas suinícolas da região oeste de Santa Catarina no período entre Agosto de 2015 e Junho de 2017. Quanto ao tamanho da amostra e a representatividade, é estatisticamente representativa ao nível de confiança de $94 \%$ com margem de erro de 6\%, sendo necessárias 244 granjas entrevistas, no caso da pesquisa utilizada como fonte de dados, possui quantidade de entrevistas superior a este valor, o que permite inferir os resultados da amostra sobre a população de granjas de suínos do Oeste Catarinense. Conforme Martins e Theóphilo (2016) a definição do instrumento de coleta deve estar relacionada com os objetivos que se pretende atingir. Estes devem direcionar de forma lógica e sistemática o processo de coleta, análise e interpretação dos dados.

\subsection{Procedimentos para análise dos dados}

Os dados foram organizados em planilhas do Excel, de maneira que permita atender aos objetivos propostos nesta pesquisa sendo que: 4 dos indicadores utilizados são categóricos (discretos) e permitiram investigar o perfil dos suinocultores do oeste Catarinense. 2 indicadores foram utilizados para mapear as características da matriz produtiva de suínos, permitindo identificar o tipo de mão de obra utilizada no desempenho das atividades de cada uma das 5 modalidades produtivas investigadas. Por último avaliou-se 4 indicadores que buscavam captar o nível de atendimento dos dispositivos da NR 9 e NR 31 no que compete ao desempenho das atividades primárias do setor suinícola de Santa Catarina. No Quadro 3, é possível verificar as perguntas selecionadas do questionário e a estratégia de abordagem dos dados utilizada nesta pesquisa. 
Quadro 1 Indicadores utilizados para análise dos dados

\begin{tabular}{|l|l|}
\hline Abordagem dos dados: Quantitativa & Abordagem dos dados: Qualitativa \\
\hline Quantas pessoas residem na propriedade rural? & Qual o sistema de alimentação a granja utiliza? \\
\hline Qual a faixa de idade do proprietário da granja? & $\begin{array}{l}\text { O integrador ou proprietário da granja, investe em } \\
\text { treinamentos profissionais e educacionais internos } \\
\text { e externos para os funcionários ou integrados? }\end{array}$ \\
\hline $\begin{array}{l}\text { Qual o nível de escolaridade do } \\
\text { proprietário/gestor? }\end{array}$ & $\begin{array}{l}\text { O integrador ou proprietário promove e preserva a } \\
\text { saúde dos integrantes da propriedade e estes } \\
\text { utilizam EPI's conforme disposto na NR 31? }\end{array}$ \\
\hline Qual a modalidade produtiva atua? & $\begin{array}{l}\text { O integrador ou proprietário da granja realiza } \\
\text { PPRA? Faz avaliação e monitoramento dos riscos } \\
\text { Biológicos, Físicos, Químicos e de Acidentes? }\end{array}$ \\
\hline $\begin{array}{l}\text { Possui funcionários registrados? Contribui com } \\
\text { beneficios de } 13^{\circ}, \text { Férias, encargos sociais? } \\
\text { Quando necessário com adicional de insalubridade } \\
\text { e pericolusidade? }\end{array}$ & \\
\hline
\end{tabular}

Fonte: Dados da pesquisa.

Com relação ao atendimento dos dispositivos da NR 09 e NR 31 foram tabuladas 4 alternativas das 265 granjas entrevistadas para cada questão relacionada as perguntas selecionadas. Ao todo foram analisadas 3710 respostas distribuídas em 5 modalidades produtivas compreendendo:

a) Unidade Produtora de Leitões (UPL);

b) Unidade Produtora de Leitões Desmamados (UPD);

c) Ciclo Completo (CC);

d) Unidades de Terminação (UT);

e) Wean To Finish (WTF) equivalente a modalidade de terminação.

Para verificar o nível de atendimento da NR 9 e NR 31 na unidade produtora (granja) avaliada, definiu-se três níveis de enquadramento, de acordo com as respostas dos suinocultores do conjunto total de granjas entrevistadas. Para tanto definiu-se as seguintes amplitudes e limites, conforme disposto no Quadro 4.

Quadro 2 Limites e amplitude para aderência de atendimento das NR

\begin{tabular}{|l|l|}
\hline 0 á $30 \%$ & Não atende \\
\hline $31 \%$ á $70 \%$ & Atende em Partes \\
\hline $71 \%$ á $100 \%$ & Atende totalmente. \\
\hline
\end{tabular}

Fonte:Elaborado pela autora.

Desta maneira, na próxima seção são apresentados os principais resultados auferidos pela pesquisa.

\section{ANALISE DOS RESULTADOS}

Após a estratificação dos resultados apurados foram elaboradas em primeiro momento as estatísticas descritivas do conjunto de granjas da amostra (n 265), de maneira que permitiu identificar 
alguns aspectos sobre o perfil do suinocultor do oeste catarinense. Na sequência, apresentam-se os resultados gerais sobre o tamanho das granjas em capacidade produtiva, quantidade de funcionários, promoção e participação de treinamentos, elaboração PPRA, avaliando os níveis de atendimento das atividades com os dispositivos da NR 9 e NR 31.

\subsection{Perfil dos suinocultores do oeste catarinense}

Na Tabela 1, são apresentados os principais resultados referentes à caracterização do perfil do suinocultor catarinense.

Tabela 1 Perfil das granjas suinícolas do Oeste Catarinense

\begin{tabular}{lr|lr|lr|lr}
\hline Experiência & $\%$ & Grupo Familiar & $\%$ & Idade Gestor & $\%$ & Escolaridade & $\%$ \\
\hline 1 ano & $2,00 \%$ & 1 a 2 pessoas & $6,42 \%$ & 20 a 31 anos & $6,79 \%$ & Fundamental & $59,66 \%$ \\
1 á 5 anos & $6,42 \%$ & 3 a 4 pessoas & $32,83 \%$ & 31 a 40 anos & $20,75 \%$ & Médio & $26,70 \%$ \\
5 a 10 anos & $17,74 \%$ & 4 a 5 pessoas & $35,09 \%$ & 41 a 50 anos & $40,00 \%$ & Técnico & $5,11 \%$ \\
10 anos ou + & $72,08 \%$ & Mais de 6 & $25,66 \%$ & 51 anos ou + & $32,45 \%$ & Superior & $8,52 \%$ \\
\hline Total & $100 \%$ & Total & $100 \%$ & Total & $100 \%$ & Total & $100 \%$ \\
\hline
\end{tabular}

Fonte: Dados da pesquisa.

Convém destacar, inicialmente que se obteve a participação de 265 granjas suinícolas da região oeste de Santa Catarina. Para esse conjunto de entidades, primeiramente procurou-se identificar qual o tempo de experiência dos produtores de suínos participantes da amostra. Conforme, a Tabela 1, evidenciase que a $3 / 4$ dos produtores possuem mais de 10 anos de experiência na atividade, nas diversas modalidades produtivas existentes, sendo relevante evidenciar que algumas destas granjas já estão na terceira geração de administradores com até 50 anos de experiência. O segundo grupo de granjas mais representativo são os produtores que possuem entre 5 e 10 anos de atividade; Já os grupos de produtores que possui entre 1 e 5 anos de experiência representam apenas $8,42 \%$ da amostra.

Estes dados permitem inferir que apesar da atividade suinícola apresentar crescimento nas últimas décadas, nesta região apresenta elevado grau de conservadorismo entre as granjas produtoras com maior experiência; Em conversa com alguns destes produtores mais experientes, estes justificam sua permanência por aspectos de parcerias sólidas com agroindústrias de longa data, sendo denominadas de processo de integração ou parceria entre (produtor e agroindústria) e também o fator de investimentos altos necessários para instalações cada vez mais modernas que demandam de maiores investimentos, que necessitam de longo prazo para retornarem a seus investidores, além do capital de giro necessário para manter atividade que tornaria muito mais oneroso para o produtor absorver todos os gastos; Desta maneira justifica-se a grande ascensão da modalidade de negócio "Integrada" para o desenvolvimento do setor e a permanência destas famílias por longas décadas na atividade.

Associado ao tempo de experiência dos agricultores produtores de suínos do oeste catarinense, evidencia-se que a idade dos gestores das granjas é predominantemente de pessoas com idade entre 40 e 50 anos, onde muitas já estão na sucessão da granja na segunda geração, ou seja, por questões culturais e por legislações pertinentes a sucessões, os descendentes das famílias assumem o controle da atividade na medida em que os tutores fundadores efetivam o ato uso fruto, doação ou espólio da propriedade. Ocorre com muita frequência, que ao assumir a granja da família (filho/a) que se responsabiliza de cuidar dos país durante toda sua vida herda de seus pares (irmãos) o direito sobre suas cotas da propriedade.

O grupo de gestores acima de 51 anos representa 32,45\% da amostra, sendo que somando grupo entre (40 e 50 anos, com aqueles com mais de 51 anos) ambos totalizam 72,45\% dos gestores das granjas participantes, corroborando com os indicadores de tempo de experiência das famílias produtoras de suínos 
entrevistadas.

Quanto ao grupo familiar predominante, o grupo entre 4 e 5 pessoas foi o mais representativo com 35,09\% das famílias da amostra, enquanto de maneira geral 67,92\% das famílias dos produtores de suínos participantes tem entre 3 e 5 pessoas no grupo familiar. Estes resultados corroboram com as características de agricultura familiar predominante nesta região do país, e vem de encontro com os dados apresentados sobre a idade dos gestores das granjas predominante ente 40 e mais de 50 anos, pois geralmente a capacidade de mão de obra disponível para desempenhar atividade, caracteriza-se pela presença de um ou dos dois pais fundadores de primeira geração, que muitas vezes já encontram-se impossibilitados de auxiliarem nas atividades da granja, de um casal de filho (sucessores) de segunda geração, o qual disponibiliza sua mão de obra para realização da atividade, com auxílio de um ou dois filhos que compõem o grupo familiar.

Quanto ao nível de instrução teórica dos gestores das granjas, conforme a Tabela $1(59,66 \%)$ possuem o ensino fundamental ou inferior, sendo representados em sua totalidade pelos gestores de primeira e segunda geração de proprietários/ fundadores das granjas. Já os níveis de instrução (médio, técnico e superior) foram representados em partes pelos gestores ou sucessores de segunda e terceira geração, sendo que o nível de instrução superior $8,52 \%$ é representado exclusivamente pela terceira geração de proprietários.

Conforme Camargo (2017), apenas 8,9\% dos filhos de terceira geração de sucessores, manifestam interesse em dar continuidade na sucessão da granja, os principais fatores motivadores desta baixa aderência dos jovens em permanecerem na atividade, reporta-se a "aposentadoria", com valores maiores quando estes trabalham em empresas ou instituições, que lhes permitiram atingir este objetivo; Outro fator apontando referem-se aos horários e rotina de trabalho melhores definidos e com direito trabalhistas garantidos como: encargos sociais (FGTS, INSS, férias e décimo terceiro), fatores que geralmente inexistem quando é alocada sua mão de obra vinculado a agricultura familiar.

\subsection{Mapeamento da matriz produtiva de suínos no oeste catarinense}

Na Tabela 2 são apresentados os principais resultados quanto a organização da cadeia produtiva de suínos na região oeste de Santa Catarina no tocante aos sistemas produtivos e a utilização da mão de obra familiar ou de terceiros.

Tabela 1 Sistemas Produtivos e a mão de obra utilizada na granja

\begin{tabular}{l|r|r|r|r|r}
\hline Modalidades Produtivas & UPL & UPD & CC & UT & WTF \\
\hline$n$ (amostral) & 58 & 24 & 16 & 151 & 16 \\
Proporção de Modalidades Produtivas & $22 \%$ & $9 \%$ & $6 \%$ & $57 \%$ & $6 \%$ \\
Sistema Produtivo Independente & $20,69 \%$ & $12,50 \%$ & $75,00 \%$ & $7,28 \%$ & $12,50 \%$ \\
Sistema Produtivo Integrado & $79,31 \%$ & $87,50 \%$ & $25,00 \%$ & $92,72 \%$ & $87,50 \%$ \\
\hline
\end{tabular}

Possui funcionários registrados? Contribui com beneficios de 13, Férias, encargos sociais? Quando necessário com adicional de insalubridade e pericolusidade?

\begin{tabular}{|c|c|c|c|c|c|}
\hline $\begin{array}{l}\text { Não tenho funcionários. Mão de Obra é } \\
\text { familiar. }\end{array}$ & $52 \%$ & $63 \%$ & $69 \%$ & $91 \%$ & $38 \%$ \\
\hline Tenho funcionários, porém sem CLT. & $0 \%$ & $4 \%$ & $6 \%$ & $1 \%$ & $6 \%$ \\
\hline $\begin{array}{l}\text { Tenho funcionários com CLT, mas sem } \\
\text { Benefícios. }\end{array}$ & $0 \%$ & $0 \%$ & $0 \%$ & $3 \%$ & $6 \%$ \\
\hline $\begin{array}{l}\text { Tenho funcionários, e contribuo com todos } \\
\text { os Benefícios. }\end{array}$ & $48 \%$ & $33 \%$ & $25 \%$ & $5 \%$ & $50 \%$ \\
\hline
\end{tabular}

Fonte: Dados da pesquisa 
De acordo com a Tabela 2, identificou que entre as cinco modalidades produtivas praticadas em escala industrial na região oeste de Santa Catarina, no geral 84,90\% são granjas que operam no sistema integração. Este resultado vem de encontro com os estudos de Miele (2006), que identificou a proporção das granjas tecnificadas de suínos que operam na modalidade integração na região sul do Brasil em $88 \%$ em 2006. Ainda, conforme dados da ABCS (2016), no ano de 2016 a proporção de produtores Integrados foi de $45 \%$ de cooperados era $39 \%$, enquanto que $16 \%$ eram produtores Independentes em Santa Catarina.

De acordo com a Tabela 2, verifica-se que entre as modalidades produtivas (UPL, UPD, UT, WTF) existem padronizações semelhantes na proporção de unidades produtoras integradas e independentes que corroboram com estes resultados, sendo que dentre estas modalidades integradas todas apresentaram nível de aderência a integração acima de $79 \%$ chegando a 92,72\% no caso das unidades de terminação.

A exceção identificou-se nas unidades produtivas de ciclo completo que apresentaram apenas $25 \%$ de aderência ao sistema de produção integrado. Cabe ressaltar que esta modalidade produtiva foi a precursora de todo desenvolvimento da cadeia produtiva, pois anterior ao período de implantação do sistema produtivo integrado que em Santa Catarina que ocorreu a partir de 1990, atividade de produção de suínos abrangia uma quantidade aproximadamente 10 vezes mais produtores (independentes) que produziam em menores escalas, e coordenavam todo seu processo de produção e venda dos suínos.

A partir da implantação do sistema produtivo integrado, a modalidade produtiva de ciclo completo (CC) sofreu forte queda de participação na produção, pois em Santa Catarina é cada vez menos incentivada pelas agroindústrias sua adesão, já que estas apresentam como metas estratégicas, que a produção primária de suínos seja especializada por fases produtivas segregadas em modalidades UPL, UPL, UT, WTF (MIELE, 2006).

Quanto aos aspectos sobre a mão de obra utilizada no desenvolvimento das atividades suinícolas, de maneira geral $75 \%$ das granjas produtoras da amostra evidenciaram que são propriedades que não possuem funcionários, caracterizando a utilização predominante da mão de obra familiar. Corrobora com este resultado os estudos de Konrad e Silva (2012), que apresentam evidencias de que agricultura familiar em Santa Catarina é relevante, a ponto de influenciar na estrutura social e no desenvolvimento economico das regiões, sendo caracterizadas por pequenas propriedades onde o próprio grupo familiar é quem administra e trabalha no processo produtivo.

Este resultado comprova-se pelo desmembramento evidenciado entre as modalidades produtivas os quais apresentaram indices de participação de mão obra familiar com variação entre (38 á 91\%) para as unidades de terminação, respectivamente nas (WTF e UT). Já nas unidades de criação (UPL, UPD e CC), estes indicadores variaram entre (52 e 69\%). O grupo de suínocultores que utilizam a mão de obra familiar consolida-se como o mais representativo entre o total de produtores. O principal recolhimento previdenciario deste grupo é o funrural $(2,3 \%)$ sobre o valor da nota fiscal de produtor emitida. No caso destes trabalhadores a legislação previdênciaria preve o prazo de recolhimento de 30 anos para o genero Masculino e de 25 anos para o genero Feminino.

Conforme a Tabela 1 menciona que dentre os $75 \%$ dos suinocultores que utilizam mão de obra familiar para desenvolver atividade, 84,7\% não atribuem valor algum para sua mão de obra ou da familia, considerando equivocadamente apenas o valor do resultado operacional bruto do lote como salário ou remuneração da atividade.

Já quanto ao grupo de granjas que possui funcionários devidamente registrados, e contribui com todos os beneficíos e encargos sociais previstos no montante geral, é representado por $21 \%$ da amostra. Compreendendo conforme disposto na Tabela 2, com maior representatividade as UPL e UPD com (48 e $33 \%$ ) de funcionarios devidamente registrados, o que evidencia que nestas modalidades existe demanda 
maior de mão de obra exclusiva para atividade, sendo necessários o revesamento de turnos, tornando inviável apenas o uso da mão de obra familiar. Já com relação as modalidades de terminação ( UT e WTF) destaca-se a representatividade das unidades WTF com 50\% demanda de funcionários para o desenvolvimento da atividade.

Conforme ABCS (2016) a modalidade produtiva Wean to Finish são unidades com padrão americano de produção que necessitam de uma estrutura em investimento diferenciada, pois o processo elimina a fase de crechário, otimizando a logística e apresentando melhores desempenhos ao final do ciclo produtivo. Esta modalidade ainda possui poucas unidades produtoras instaladas em Santa Catarina, no entanto é possível evidenciar a maior demanda de mão de obra e cuidados para desempenha-la ao comparar com a necessidade de mão de obra das unidades de terminação (UT).

\subsection{NÍVEIS DE ATENDIMENTO DAS ATIVIDADES SUINÍCOLAS COM NR 9 E NR 31}

Na Tabela 3, são apresentados os principais pontos que foram investigados quanto ao atendimento da NR 09 e NR 31 nas unidades produtoras de suínos dos suínos na região oeste de Santa Catarina.

Tabela 3 Atendimento NR 31 em granjas suinícolas do Oeste catarinense

\begin{tabular}{|c|c|c|c|c|c|}
\hline Modalidades Produtivas & UPL & UPD & $\mathbf{C C}$ & UT & WTF \\
\hline$n$ (amostral) & 58 & 24 & 16 & 151 & 16 \\
\hline Sistema de Alimentação Manual & $47 \%$ & $58 \%$ & $75 \%$ & $58 \%$ & $50 \%$ \\
\hline Sistema de Alimentação Automático & $53 \%$ & $41 \%$ & $25 \%$ & $41 \%$ & $50 \%$ \\
\hline \multicolumn{6}{|c|}{$\begin{array}{l}\text { O integrador ou proprietário da granja, investe em treinamentos profissionais e educacionais } \\
\text { internos e externos para os funcionários ou integrados? }\end{array}$} \\
\hline Não investe em nenhum treinamento interno ou externo. & $53 \%$ & $50 \%$ & $63 \%$ & $6 \%$ & $31 \%$ \\
\hline Investe em alguns treinamentos operacional. & $10 \%$ & $13 \%$ & $6 \%$ & $1 \%$ & $38 \%$ \\
\hline Investe em alguns treinamentos de tratamento resíc & $26 \%$ & $21 \%$ & $13 \%$ & $1 \%$ & $19 \%$ \\
\hline Sim, investe em treinamentos frequentemente. & $10 \%$ & $17 \%$ & $19 \%$ & $3 \%$ & $13 \%$ \\
\hline \multicolumn{6}{|c|}{$\begin{array}{l}\text { O integrador ou proprietário promove e preserva a saúde dos integrantes da propriedade e estes } \\
\text { utilizam EPI's conforme disposto na NR } 31 \text { ? }\end{array}$} \\
\hline Não utilizo EPI's. & $26 \%$ & $29 \%$ & $56 \%$ & $36 \%$ & $25 \%$ \\
\hline Orienta á usar EPI, ma & $24 \%$ & $21 \%$ & $6 \%$ & $34 \%$ & $31 \%$ \\
\hline Disponibiliza os EPIs, mas não realiza treinamentos. & $36 \%$ & $29 \%$ & $13 \%$ & $18 \%$ & $25 \%$ \\
\hline Disponibiliza os EPIs e realiza treinamentos. & $14 \%$ & $21 \%$ & $25 \%$ & $13 \%$ & $19 \%$ \\
\hline \multicolumn{6}{|c|}{$\begin{array}{l}\text { O integrador ou proprietário da granja realiza PPRA? Faz avaliação e monitoramento dos riscos } \\
\text { Biológicos, Físicos, Químicos e de Acidentes? }\end{array}$} \\
\hline Não conheço oque é PPRA. & $29 \%$ & $38 \%$ & $31 \%$ & $26 \%$ & $13 \%$ \\
\hline Não realizo PPRA na granja. & $24 \%$ & $8 \%$ & $38 \%$ & $40 \%$ & $13 \%$ \\
\hline Trabalho preventivamente, mas não em nível de PPRA & $36 \%$ & $50 \%$ & $19 \%$ & $29 \%$ & $63 \%$ \\
\hline Realizo PPRA na granja. & $10 \%$ & $4 \%$ & $13 \%$ & $4 \%$ & $13 \%$ \\
\hline
\end{tabular}

Fonte: Dados da pesquisa.

Na Tabela 3 inicialmente identificou-se o sistema de alimentação (arraçoamento) utilizado pelos suinocultores, que evidenciaram de maneira geral que $58 \%$ possuem o sistema manual para alimentar seus rebanhos. Esse sistema de alimentação tem como principal incentivo inicial à demanda por menores gastos em investimentos, pois é realizado através de carro de mão, com cuba em poliuretano e armação em ferro, com peso de tara em média de $34 \mathrm{~kg}$. Já a distribuição nos comedouros, é realizada manualmente com auxílio de (pá dosadora), está modalidade apesar de inicialmente demandar de investimentos relativamente baixos em infraestrutura por parte do produtor apresenta como pontos desfavoráveis maiores demandas 
com mão de obra (própria ou terceirizada) do suinocultor para realizar a distribuição da ração nos horários pré-definidos conforme a orientação dos zootecnistas ou técnicos agrícolas que acompanham a propriedade. Ou seja, o produtor precisará estar com dedicação exclusiva nesta função.

Outro fator negativo deste sistema de alimentação é o aspecto desigual na conversão alimentar entre um lote e outro, sendo que esta é uma das variáveis econômicas muito utilizadas para remunerar o produtor, o que pode prejudicar o desempenho do lote e é muito relevante na composição do preço pago ao produtor ou vendido pelo independente (ALLEGRETTI, 2013).

Com relação as modalidades produtivas, as UPD e UT são as que apresentam maiores proporções de granjas ainda não automatizadas com relação ao sistema de arraçoamento, apresentando níveis de $58,33 \%$ e 58,28\% respectivamente, enquanto que a modalidade UPL foi a que apresentou menor proporção de granjas com este sistema representada por $46,55 \%$.

No que tange as granjas da modalidade CC estas apresentaram $75 \%$ do total de granjas com o sistema alimentação manual. Este resultado vem de encontro com os apresentados pelas características mercadológicas da organização da cadeia produtiva suinícola em Santa Catarina, que sofreu uma transformação a partir de 1990 incentivar o desenvolvimento do sistema de produção integrado, que apresenta como característica principal a divisão de investimentos e dos riscos mercadológicos entre o produtor e agroindústria. $\mathrm{O}$ fator negativo deste sistema produtivo em comparação com o sistema de produção independente é o retorno final para o agricultor, que perde autonomia em termos de negociação do produto pronto com relação ao mercado spot, e tem sua remuneração paga através do acerto do lote, onde são avaliados uma série de metas e indicadores, dentre eles o indicador de conversão alimentar (MIELE; WAQUIL, 2007).

Com relação as diversas proporções de granjas produtoras de suínos, em distintas modalidades entre $46,55 \%$ e $75 \%$ infere-se que é representativa a quantidade de agricultores que ainda realizam o sistema de arraçoamento de maneira manual, utilizando carro de mão e pá dosadora para sua distribuição, neste aspecto identifica-se que existe um ótima demanda para disponibilizar cursos, treinamentos e orientação dos trabalhadores rurais desta atividade, no tocante a NR 31, sobre tudo no parágrafo 31.10 que trata da Ergonomia nas atividades agrícolas e pecuárias, e que normatiza os procedimentos a serem tomados pelo empregador rural (produtor Independente) ou equiparado (Integrador) quanto a adaptações de trabalho às características psicofisiológicas dos trabalhadores, de modo a proporcionar melhorias nas condições de conforto e segurança no trabalho.

Conforme os estudos de Rocha Maia e Rodrigues (2012), a NR 31 estabelece que, quando houver escadas, rampas, corredores e outras áreas destinadas à circulação de trabalhadores e à movimentação de materiais, que ofereçam risco de escorregamento, devem ser empregados materiais ou processos antiderrapantes e dispor de proteção contra o risco de queda, logo, as observações supracitadas contrastam com o preconizado na legislação vigente.

Evidencia-se que ausência de treinamento e orientação sobre estes aspectos comprometem também aos dispostos no parágrafo 31.10.3 o qual determina que para todo transporte manual de cargas, o trabalhador deve receber treinamento e quanto aos métodos de trabalho e de prevenção dos acidentes. Estendendo-se ao disposto no parágrafo 31.10 .4 o qual prevê que todo o transporte carga ou descarga de materiais realizados por impulsão ou tração sobre trilhos ou carro de mão, devem ser executados de maneira compatível com a saúde, segurança e capacidade de força do trabalhador.

Quanto aos treinamentos internos e externos para funcionários ou integrados, verificou-se que de maneira geral, $58 \%$ dos integradores ou empregadores não oferecem nenhum tipo de treinamento a seus funcionários ou integrados. Enquanto que $12 \%$ da amostra evidencia que realizou treinamentos voltados para manejo ambiental (operacional), outros $22 \%$ dos produtores declararam que já realizaram 
treinamentos sobre tratamento de resíduos e um quarto grupo de produtores representando $8 \%$ da amostra evidenciaram que realizam todos os treinamentos internos e externos proporcionados pelo empregador ou integrador.

Conforme o Tabela 3, dentre o grupo de granjas que realiza todos os treinamentos disponibilizados, observa-se maior desempenho para a modalidade CC com 19\% de representatividade, quanto estas possuem funcionários, e também com maior participação de não investimento em treinamentos quando não possui funcionários e trabalha apenas com a mão de obra familiar representado por $63 \%$ da modalidade de CC. A segunda modalidade que realiza mais treinamentos é as UPD com $17 \%$ seguida das WTF com 13\%; Em quarto momento estão as unidades UPL com 10\% de participação em todos os treinamentos. A modalidade com menor participação em treinamentos sobre CIPATR foi a modalidade UT.

Conforme disposto na NR 31 parágrafos 31.7. 20 que trata dos treinamentos, a norma estabelece que cabe ao empregador rural ou equiparado (Integrador) promover treinamentos sobre segurança e saúde no trabalho para os membros do CIPATR; estes, devem estar aptos a reaplicar treinamentos para os trabalhadores rurais, ao mínimo sobre os temas elencados na NR 31, parágrafo 31.7.20.1(2005, p. 8):

a) noções de organização, funcionamento, importância e atuação da CIPATR;

b) estudo das condições de trabalho com análise dos riscos originados do processo produtivo no campo, bem como medidas de controle (por exemplo, nos temas agrotóxicos, maquinas e equipamentos, riscos com eletricidade, animais peçonhentos, ferramentas, silos e armazéns, transporte de trabalhadores, fatores climáticos e topográficos, áreas de vivência, ergonomia e organização do trabalho);

c) caracterização e estudo de acidentes ou doenças do trabalho, metodologia de investigação e análise;

d) noções de primeiros socorros;

e) noções de prevenção de DST, AIDS e dependências químicas;

f) noções sobre legislação trabalhista e previdenciária relativa à Segurança e Saúde no Trabalho;

g) noções sobre prevenção e combate a incêndios;

h) princípios gerais de higiene no trabalho;

i) relações humanas no trabalho;

j) proteção de máquinas equipamentos;

k) noções de ergonomia.

Neste sentido os resultados apresentados permitem inferir que os empregadores rurais ou equiparados (Integradores) atendem em partes ao disposto na NR 31, já que 42\% da amostra realiza algum treinamento. No entanto (34/47) 80,95\% destes trabalhadores receberam treinamentos com foco em manejo e tratamento de resíduos, que estão vinculados ás legislações ambientais, sobre tudo as dispostas na Instrução Normativa (IN-11) FATMA, que é o órgão que fiscaliza e autua os impactos ambientais da atividade suinícola em Santa Catarina. Contudo infere-se que é baixa aderência especifica e o foco de treinamentos em NR 31 no que se refere aos dispostos sobre obrigatoriedade de efetuar e disponibilizar treinamentos do Empregador ou equiparado (Integrador) para os trabalhadores rurais suinocultores representados como efetiva, apenas por $8 \%$ do total da amostra.

$\mathrm{Na}$ sequência procurou-se identificar se o Empregador ou Integrador disponibilizava EPI's procurando preservar a saúde dos funcionários e dos integrantes da propriedade rural. Como principais resultados, observou-se que existe alto índice de não atendimento da NR 31 por parte dos trabalhadores rurais suinocultores da amostra, de encontro com Araújo e Oliveira (2017) precariedade dos mecanismos de vigilância da saúde, pelo uso inadequado ou falta de equipamentos de proteção coletiva e individual, o 
qual é agravada pelas precárias condições socioeconômicas e culturais da grande maioria dos trabalhadores rurais, o que amplia sua vulnerabilidade frente à toxicidade dos agrotóxicos. Entre as cinco modalidades investigadas, evidenciou-se que 56\% da modalidade de CC afirma não utilizar EPI's, enquanto que apenas $25 \%$ dos produtores rurais desta modalidade, afirmam que o Empregador ou Integrador disponibiliza EPI's e treina seus trabalhadores.

Quanto a modalidade produtiva que afirmou, ser orientada ao uso de EPI's, mas que porém não lhe é fornecida gratuitamente, destaca-se as granjas UT representando 34\% dos trabalhadores desta modalidade neste quesito investigado. Observa-se que quanto a realização de treinamentos e a disponibilização dos EPI's pelo Empregador ou Integrador, nesta modalidade apenas 13\% dos trabalhadores confirmaram esta prática. No que refere-se as modalidades produtivas que recebem os EPI's, mas não recebem os treinamentos adequados identificou-se que as unidades UPL e UPD foram as mais representativas ambas com (36\% e $29 \%)$ de trabalhadores nesta situação.

Sobre a efetividade da realização de treinamentos para o uso EPI's e a sua disponibilização para os suinocultores, com base na amostra, evidenciou-se que de maneira geral entre as 265 granjas da investigadas apenas $15 \%$ disponibilizam EPI's gratuitamente aos empregados/integrados e realizam treinamentos.

De acordo com Barroso (2012), o empregador rural ou equiparado deve proporcionar capacitação sobre a correta utilização dos equipamentos de proteção individual. $\mathrm{O}$ simples fornecimento dos equipamentos de proteção individual não garante a proteção da saúde do trabalhador e nem evita contaminações. Incorretamente utilizados, os EPI's podem comprometer ainda mais a segurança do trabalhador.

A partir dos dados evidenciados infere-se que é baixo nível de aderência da NR 31 no que tange os aspectos do parágrafo 31.20 que trata das medidas de proteção pessoal. Primeiramente é altamente preocupante a quantidade de $34 \%$ trabalhadores rurais suinocultores ou integrados que afirmam não utilizar os EPI durante suas atividades cotidianas por estes não serem disponibilizados gratuitamente, não atendendo a NR 31.20. Enquanto que $29 \%$ da amostra atende em partes ao disposto no parágrafo 31.20.1 que estabelece o fornecimento de EPI's deve ser gratuito, neste grupo os produtores afirmam serem orientados a utilizar, porém o empregador ou equiparado não disponibiliza gratuitamente.

Conforme a NR 31, o parágrafo 31.20.2 o empregador rural ou equiparado (Integrador) deverá fornecer aos trabalhadores, de acordo com as necessidades de cada atividade os seguintes equipamentos de proteção individual:

a) Proteção da cabeça, olhos e face;

b) Óculos contrairritação e outras lesões;

c) Proteção auditiva;

d) Proteção das vias respiratórias;

e) Proteção aos membros inferiores;

f) Proteção aos membros superiores;

g) Proteção do corpo inteiro nos trabalhos que haja perigo de lesões provocadas por agentes de origem térmica, biológica, mecânica, meteorológica e química;

h) Proteção contra quedas com diferença de nível.

Neste sentido, convém apresentar que $23 \%$ do total de trabalhadores rurais produtores de suínos da amostra, afirmou que recebe os EPI's gratuitamente, porém não recebem treinamentos preventivos e de utilização, sendo que este grupo atende em partes o disposto na NR 31.20. Já o grupo de trabalhadores, 
que contemplam totalmente a NR 31.20 , representando $15 \%$ do conjunto total das modalidades produtivas da amostra.

Estes resultados vem de encontro com a pesquisa de Machado e Cardoso (2007), que pesquisaram aderência da NR 31 em trabalhadores que operavam colheita florestal, sendo que encontraram todos os funcionário sem uso de qualquer EPI's previsto na norma; Destes funcionários $23 \%$ eram terceirizados e $77 \%$ eram funcionários diretos, de acordo com os autores esses resultados surpreendem pelo elevado porcentual de trabalhadores que não fazem uso de EPI nas atividadesde florestais, apesar de a sua necessidade ser evidente.

Conforme Silva, Barbosa e Dos Santos (2016) embora se discuta discretamente sobre medidas de prevenção no trabalho rural e riscos e doenças decorrentes da falta de proteção durante o trabalho agricola, a degradação das condições de trabalho e da qualidade de vida dos trabalhadores continuam configurando situações em que o trabalhador rural se expõe a uma diversidade de riscos ocupacionais. Sendo assim, é necessário que sejam implantados, programas de educação continuada com treinamentos teóricos e práticos referentes à utilização dos EPI's com o intuito de adaptar as informações ao trabalhador rural para que este seja educado e habituado a usar os dispositivos de proteção.

Os aspectos relacionados com a realização de PPRA, buscando identificar se o empregador rural ou Integrador realiza avaliações e monitoramento quanto aos riscos Biológicos, Físicos, Químicos, Acidentes e ergonômicos, decorrentes do desenvolvimento da atividade, identificou-se que (28\% e 32\%) dos trabalhadores das modalidades produtivas de suínos em geral não conhecem ou não realizam PPRA em suas propriedades para desenvolver suas atividades.

Ainda um terceiro grupo de granjas representando 34\% das modalidades produtivas de suínos afirmam que realizam prevenções em suas unidades produtoras, mas desconhecem se é em nível ou efetivamente um PPRA. Enquanto que um grupo mais restrito de apenas $6 \%$ dos produtores, afirmam que realiza avaliações e monitoramento dos riscos Biológicos, físicos, químicos ou de acidentes antes do desenvolvimento das atividades. Dentre o grupo de praticantes do PPRA, identificou-se que as modalidades produtivas mais representativas foram as CC e WTF ambas com 13\% das granjas, a modalidade UPL com $10 \%$ das granjas, enquanto que as modalidades UPD e UT representaram apenas $4 \%$ deste grupo.

Apesar do PPRA fazer parte do conjunto mais amplo campo da preservação da saúde e da integridade dos trabalhadores, devendo estar articulado com o disposto nas demais NR, em especial com o Programa de Controle Médico de Saúde Ocupacional - PCMSO previsto na NR-7. Os resultados nos permitem inferir que existe um alto índice de unidades produtoras de suínos da amostra $60 \%$ que não realizam o PPRA. Enquanto que o grupo de realiza PPRA, representa apenas $6 \%$ do total das unidades produtoras de suínos da região oeste de Santa Catarina. Permitindo inferir que existem um baixo nível de aderência dos dispositivos da NR 9 no que se refere as unidades primárias de produção de suínos em Santa Catarina, mesmo que deste total cerca de $85 \%$ sejam unidades Integradas a parceiros comerciais, integrantes de grandes players do agronegócio mundial.

No parágrafo 9.1 e 9. 1.1 da NR 9, são apresentados os campos de atuação desta NR, os quais preveem a obrigatoriedade da elaboração e implementação, por parte de todos os empregadores e instituições que admitam trabalhadores como empregados, do Programa de Prevenção de Riscos Ambientais - PPRA, visando à preservação da saúde e da integridade dos trabalhadores, através da antecipação, reconhecimento, avaliação e consequente controle da ocorrência de riscos ambientais existentes ou que venham a existir no ambiente de trabalho, tendo em consideração a proteção do meio ambiente e dos recursos naturais. Embora exista a previsão legal, esta pesquisa nos revela dados com alto índice entre $(60 \%)$ de "não atendimento" ao disposto na NR 9 que trata do PPRA com relação as 
granjas suinícolas da amostra.

Conforme estudos de Dos Santos Alonço (2006), a melhoria das condições de trabalho é feita pela análise das condições físicas de trabalho, como temperatura, ruídos e vibrações. O desconforto térmico e as vibrações são os principais fatores que afetam o comportamento normal das pessoas, visto que existe uma taxa aceitável de exposição tolerável pelo ser humano, portanto o não atendimento dos dispostivos da NR 31 e NR 9 é mais um flagrante de desrespeito dos empregadores ou equiparados pelo não cumprimento de tais NRs.

\section{CONCLUSÃO}

Esta pesquisa teve como objetivo geral identificar os níveis de atendimento da NR 9 e NR 31 no desenvolvimento das atividades suinícolas das granjas do oeste catarinense. Através da classificação da aderência ou não dos dispositivos previstos nas referidas NR, de acordo com os limites e amplitude de atendimento em três níveis:

a) zero á $30 \%$ do total de granjas, classifica-se como "Não atende".

b) $31 \%$ á $70 \%$ do total de granjas, classifica-se como "Atende em partes"

c) $71 \%$ á $100 \%$ do total de granjas, classifica-se como "Atende totalmente".

Identificou-se o mapeamento da matriz produtiva primária de suínos através da identificação da proporção dos sistemas produtivos, das modalidades produtivas, do sistema de alimentação e do tipo de mão de obra utilizada.

Quanto a contratação própria de mão de obra para desempenhar as atividades suinícolas da granja, $75 \%$ da amostra, declarou não possuir funcionário, dependendo exclusivamente de utilizar a mão de obra familiar para o desenvolvimento da atividade. Estas granjas geralmente tem o porte de pequeno e médio para ser atendida pela família. No entanto $25 \%$ das granjas podem ser consideradas de grande porte, e possuem funcionários contratados para realizar as atividades.

Quanto ao escopo da aplicação da NR 9 e da NR 31, ambas as normas estabelecem responsabilidades para os empregadores ou equiparados quanto aos aspectos de segurança e saúde do trabalhador. No caso dos produtores da agricultura familiar, podem ser considerados como funcionários das grandes agroindústrias, denominadas "Integradoras".

Quanto ao atendimento da responsabilidade de realizar treinamentos do empregador ou equiparado, os produtores declararam que 58\% dos integradores ou empregadores não oferecem nenhum tipo de treinamento a seus funcionários ou integrados, ou seja, não atendem a NR 9 e NR 31. Quanto aos grupos que declaram realizar treinamentos mesmo que voltados mais para aspectos ambientais que em segurança e saúde, permitem consideram que 34\% dos produtores, "Atendem em partes" as regulamentações sobre responsabilidade de treinamentos. Já um pequeno grupo de cerca de $8 \%$ das granjas, demostra "Atendimento total" as diretrizes de treinamentos dispostos neste e em outras NR.

De maneira global no quesito "treinamentos" os grupos que atendem em partes e apresentam atendimento total as NR, representam juntas $42 \%$ de conformidade, ou seja, o nível de atendimento aos quesitos responsabilidade do empregador ou equiparado, indica que existe deficiências por parte dos empregadores ou da fiscalização permitindo evidenciar índices tão elevados de não atendimento.

Com relação ao nível de atendimento da NR 31.20, sobre os aspectos de treinamentos e disponibilização de EPI's, os principais resultados identificados permitem inferir que $34 \%$ das granjas "Não atendem" a este dispositivo. Já o grupo de granjas que atende em partes os dispositivos da NR 31.20 
representa $52 \%$ dos suinocultores, enquanto que o grupo de suinocultores que afirmam "Atender totalmente" este dispositivo representa apenas $14 \%$ do total de suinocultores entrevistados.

Sob os aspectos dos níveis de atendimento da NR 9, que trata da realização preventiva de PPRA, os principais resultados identificados permitem inferir que $60 \%$ das granjas entrevistas não realizam ou não conhecem o que é PPRA, evidenciando que este total de granjas "Não atendem" os dispositivos da NR 9. Quanto ao grupo de $24 \%$ do total de granjas que realizam trabalhos de prevenção, porém não sabe se em nível de PPRA, considerou-se que estes "Atendem em partes" aos dispositivos da NR 9. Já o grupo que apresentou melhor desempenho, afirmando que "Atende totalmente" aos dispositivos da NR 9, representou apenas $6 \%$ do total de unidades produtoras pesquisadas.

Em resposta ao problema de pesquisa que buscava identificar quais os níveis de atendimento dos dispositivos da NR 9 e NR 31 no desenvolvimento das atividades suinícolas das granjas do oeste Catarinense, entende-se que a pesquisa atingiu seus objetivos específicos e atendeu plenamente a questão de pesquisa, conclui-se que os suinocultores do oeste catarinense estão vulneráveis, quanto ao atendimento dos dispositivos da NR 9 e NR 31, sobre tudo esta última NR 31, que trata especificamente da saúde e segurança do trabalhador rural, pois os índices mais representativos indicam que $(58 \%, 34 \%$ e $60 \%)$ das unidades produtoras foram classificadas com "Não atendimento", resultado considerado elevado. Esses resultados fornecem subsídios aos órgãos públicos para acompanhar/minimizar as ações que devem ser tomadas com relação ao atendimento pleno destas NRs. Estas informações tornam relevantes e permitem sugerir que as autoridades competentes desenvolvam mecanismos de fiscalização e controle preventivo, do atendimento ou não destes dispositivos com vistas a proteger o maior patrimônio do trabalhador, que é sua vida com saúde e segurança.

Dentre as principais limitações da pesquisa, destaca-se o fato da baixa disponibilidade de materiais correlatos sobre a temática NR 31 e o setor de suinícola para realização de cruzamento dos dados obtidos, e a concentração da pesquisa na região oeste de Santa Catarina. Como recomendações para pesquisas futuras sugere-se reaplicar esta pesquisa em outras regiões produtora de suínos ou até mesmo em outras cadeias produtivas, permitindo a comparação dos niveis de atendimento em outros setores, podendo ampliar a investigação para os demais dispositivos que contemplam as NR 9 e NR 31.

\section{REFERÊNCIAS}

ALLEGRETTI, G. Integração das dimensões social, ambiental e econômica na terminação de suínos: construção de indicadores de desempenho e validação em um município do Rio Grande do Sul. 2013.146 f. Dissertação (Mestrado) Universidade Federal do Rio Grande do Sul, Centro de Estudos e Pesquisas em Agronegócios, Programa de Pós-graduação em Agronegócios, Porto Alegre.

ARAÚJO, I.; OLIVEIRA, A. Agronegócio e agrotóxicos: impactos à saúde dos trabalhadores agrícolas no nordeste brasileiro. Revista Trabalho, Educação e Saúde, Rio de Janeiro , v. 15, n. 1, p. 117-129, abr. 2017.

ABCS- ASSOCIAÇÃO BRASILEIRA DE CRIADORES DE SUÍNOS. Mapeamento da suinocultura brasileira. 2016. Disponível em: http://www.abcs.org.br/images/-01_mapeamento_completo_bloq.pdf. Acesso em 10 set. 2017.

\section{ABPA- ASSOCIAÇÃO BRASILEIRA DE PROTEÍNA ANIMAL. Relatório Anual da ABPA 2017.} 2016. Disponível em: http://abpabr.com.br/storage/files/3678c final abpa relatorio anual 2016 portugues web reduzido.pdf. Acesso em 19 set. 2017. 
BARROSO, L.; WOLFF, D. Riscos e segurança do aplicador de agrotóxicos no Brasil. Revista

Engenharia Ambiental: Pesquisa e Tecnologia, v. 9, n. 3, 2012.

BRASIL. Ministério do Trabalho e Emprego. Norma Regulamentadora 31 Segurança e saúde no trabalho na agricultura, pecuária silvicultura, exploração florestal e aqüicultura. Portaria $\mathrm{GM} \mathrm{n}^{\circ} 86$, de 03 de março de 2005. Brasília, DF, 2005. Disponível em: <http://www.mte.gov.br> Acesso em: 09 set. 2017.

BRASIL. Ministério do Trabalho e Emprego. Norma Regulamentadora 09 Programa De Prevençê de Riscos Ambientais. Portaria MTb n. ${ }^{\circ}$ 871, de 06 de julho de 2017. Brasília, DF, 2017. Disponível em: <http://www.mte.gov.br> Acesso em: 09 set. 2017.

CAMARGO, T.; F. Análise comparativa dos níveis de sustentabilidade de granjas produtoras de suínos do oeste Catarinense. 2017. 196 f. Dissertação (Mestrado em Ciências Contábeis e Administração) - Programa de Pós-Graduação em Ciências Contábeis da Universidade Comunitária da Região de Chapecó.

DOS SANTOS ALONÇO, A. Análise ergonômica do trabalho em atividades desenvolvidas com uma roçadora manual motorizada. Revista Ciência Rural, v. 36, n. 5, p. 1638-1642, 2006.

ENGELAGE, E.et al. Análise de custos e da agregação de valor em uma granja de suínos localizada na região oeste do estado de Santa Catarina. Revista ambiente contábil, v. 9, n. 1, p. 306-323, 2017.

FARIA, N.; MÜLLER, X.. Farm work, dust exposure and respiratory symptoms among farmers. Revista de Saúde Pública, v. 40, n. 5, p. 827-836, 2006.

GIL, A.C. Métodos e técnicas de pesquisa social. 5. ed. São Paulo: Atlas, 1999.

KONRAD, J.; SILVA, C.; A. Agricultura Familiar No Oeste Catarinense:Da Colônia À Integração. XXI Encontro Nacional de Geografia Agrária. 2012. Universidade Federal de Uberlândia.

MACHADO CARDOSO, C. Avaliação das condições de segurança do trabalho na colheita e transporte florestal em propriedades rurais fomentadas no Estado do Espírito Santo. Revista Árvore, v. 31, n. 3, 2007.

MARTINS, G. A.; THEÓPHILO, C. R. Metodologia da Investigação cientifica. 3 ed. São Paulo: Atlas, 2016.

MIELE, M. Contratos, especialização, escala de produção e potencial poluidor na suinocultura de Santa Catarina. 2006. 286 f. Tese (Doutorado) - Programa de Pós-Graduação em Agronegócios, Centro de Estudos e Pesquisas em Agronegócios, Universidade Federal do Rio Grande do Sul, Porto Alegre.

MIELE, M.; WAQUIL, P. D. Estrutura e Dinâmica dos Contratos na Suinocultura de Santa Catarina: Um Estudo de Casos Múltiplos. Revista Estudos Econômicos, v. 37. n. 4, p. 817-847. 2007.

RAUPP, F. M.; BEUREN, I. M. Metodologia de pesquisas aplicadas a ciências sociais. In: BEUREN, I. M. (Org.). Como elaborar trabalhos monográficos em contabilidade: teoria e prática. 3. ed. São Paulo: Atlas, 2008. p. 76-96.

ROCHA, M.; L.; BRITO R.; L. Saúde e segurança no ambiente rural: uma análise das condições de trabalho em um setor de ordenha. Revista Ciência Rural, v. 42, n. 6, 2012.

SILVA, R.; C.; BARBOSA, M.; W.; A.; DOS SANTOS, G.; S. A utilização de equipamentos de proteção individual (EPI's) por lavradores cafeeiros do município de Rosário da Limeira (MG): uma avaliação em saúde sob a ótica do enfermeiro. Revista científica da faminas, v. 6, n. 2, 2016. 